\title{
INFLUÊNCIA DOS CURSOS TÉCNICOS DO EIXO DE RECURSOS NATURAIS NO DESENVOLVIMENTO DA CONSCIÊNCIA AMBIENTAL DOS ALUNOS DO INSTITUTO FEDERAL FLUMINENSE, CAMPUS AVANÇADO CAMBUCI
}

\author{
Kissila França Lima ${ }^{1}$ \\ Tatiana Almeida Machado 2 \\ Marize Bastos de Matos ${ }^{3}$ \\ Wanderson Souza Rabello ${ }^{4}$
}

Resumo: $O$ presente artigo analisa como os cursos técnicos na área de recursos naturais podem funcionar como instrumento de Educação Ambiental, contribuindo no desenvolvimento da consciência ambiental dos alunos do ensino médio técnico integrado em agropecuária e agroecologia, do Instituto Federal de Educação, Ciência e Tecnologia Fluminense, campus avançado Cambuci. Foi realizada uma pesquisa quali-quantitativa, com aplicação de questionários estruturados em abril de 2017, demonstrando assim, que a escola tem cumprido seu papel de promover a Educação Ambiental por meio dos cursos técnicos ofertados, e também no desenvolvimento da consciência ambiental dos discentes avaliados.

Palavras chave: Educação Ambiental; Consciência Ambiental; Meio Ambiente. 


\title{
Introdução
}

Os recursos naturais sempre foram utilizados pelo homem como uma fonte inesgotável, de forma predatória, sendo explorado indiscriminadamente para satisfazer as necessidades humanas. E a medida que o tempo passa, percebe-se que o meio ambiente tem sido cada vez mais degradado, devido ações antrópicas impensadas sobre ele, afetando drasticamente a qualidade de vida das pessoas. Segundo Leff (2006 apud CUBA, 2010 p. 25),

\begin{abstract}
a problemática ambiental não é ideologicamente neutra nem é alheia a interesses econômicos e sociais. Sua gênese dá-se num processo histórico dominado pela expansão do modo de produção capitalista, pelos padrões tecnológicos gerados por uma racionalidade econômica a curto prazo, numa ordem econômica mundial marcada pela desigualdade entre nações e classes sociais. Este processo gerou, assim, efeitos econômicos, ecológicos e culturais desiguais sobre diferentes regiões, populações, classes e grupos sociais [...].
\end{abstract}

Pode-se perceber então, que as questões ambientais, estão relacionadas ao modo de viver capitalista, ou seja, estamos imersos à ordem do capital, pensamos e agimos de acordo com suas premissas, trazendo consequências éticas devastadoras, estabelecendo um cenário de crise ambiental (GREGORI; ARAÚJO, 2013, p. 704). Por isso torna-se de extrema relevância e necessidade que a sociedade seja sensibilizada e desenvolva também a consciência ambiental, sendo estes os primeiros passos para a mudança de comportamento, auxiliando diretamente na conservação dos recursos naturais.

Diante dessa realidade, a Educação Ambiental é vista como instrumento de conscientização e da busca pela sustentabilidade para toda sociedade, com a finalidade de utilizar os recursos naturais de forma racional e conservacionista. Almeida (2011, p. 11) afirma que a utilização dos recursos naturais, inteligentemente realizada, deve subordinar-se aos princípios maiores de uma vida digna, sem que o interesse econômico cego prevaleça sobre o interesse comum da sobrevivência da humanidade e do próprio planeta.

A escola sempre foi uma importante referência na vida da sociedade, sendo um espaço de defesa civil, de transmissão de valores culturais ou de produção de conhecimento, estando no centro do debate sobre a busca de sustentabilidade, de forma a incentivar o pensamento crítico sobre a nossa realidade socioambiental (MEC, 2010, p.9). Ela é um local privilegiado, como referência de ação transformadora e de conscientização das pessoas, fazendo parte da sua missão orientar todas as pessoas sobre as mudanças sociais e ambientais que o mundo se defronta atualmente. A escola, então, como um 
multiplicador, é o melhor local onde esta proposta pedagógica (Educação Ambiental) possa surtir efeito (PETRIS; SEHNEN, 2011, p. 38).

Escolas que possuem cursos técnicos profissionalizantes no eixo de recursos naturais, possuem um papel importante na formação e também na conscientização de seus alunos, espera-se que estas formem profissionais que ao atuarem no mercado de trabalho, atuem com ética e consciência em relação às questões socioambientais, com atitudes e competências voltadas para a conservação do meio ambiente.

Tendo em vista o contexto explicitado acima, este trabalho teve como objetivo, analisar como os cursos técnicos na área de recursos naturais podem funcionar como instrumento de Educação Ambiental para os alunos do ensino médio do Instituto Federal Fluminense campus Avançado Cambuci, identificando se e como esses cursos podem influenciar no desenvolvimento da consciência ambiental desses discentes.

\section{Revisão de literatura}

\section{A Educação Ambiental nas escolas como ferramenta de conscientização ambiental}

A Educação Ambiental é um tema que ao longo dos anos vem ganhando espaço, devido às discussões sobre a problemática ambiental já fazerem parte do nosso cotidiano. Sendo um tema muito abrangente, permite conhecer de forma mais aprofundada o meio ambiente e a nossa relação com ele, mais também, fazer uma análise social, econômica, ecológica do meio urbano ou rural, repensando nossas ações dia após dia em relação ao meio em que vivemos, de forma que possamos por intermédio da conscientização ambiental, agir localmente, pensando globalmente (PETRIS; SEHNEN, 2011, p.37).

A Legislação Ambiental Brasileira em sua Constituição Federal de 1988, no seu artigo 225 afirma que "todos têm direito ao meio ambiente ecologicamente equilibrado, bem de uso comum do povo e essencial à sadia qualidade de vida, impondo se ao Poder Público e à coletividade o dever de defendê lo e preservá lo, para as presentes e futuras gerações" (BRASIL, 1988). Dessa forma, para assegurar a efetividade desse direito, é dever do poder público promover a Educação Ambiental para todos os níveis de ensino e a conscientização pública para preservação do meio ambiente.

A Política Nacional de Educação Ambiental, regulamentada pela Lei № 9.795, de 27 de abril 1999, apresenta-se então, definindo Educação Ambiental, no artigo $1^{\circ}$ como:

[...] processos por meio dos quais o indivíduo e a coletividade constroem valores sociais, conhecimentos, habilidades, atitudes e competências voltadas para a conservação do meio ambiente, bem de uso comum do povo, essencial à sadia qualidade de vida e sua sustentabilidade (BRASIL,1999). 
Esta lei pondera assim, a importância da Educação Ambiental, tendo em vista que a mesma é apontada como um componente essencial e permanente da educação nacional, devendo estar presente, de forma articulada, em todos os níveis e modalidades do processo educativo, em caráter formal e nãoformal, e ser desenvolvida no âmbito dos currículos das instituições de ensino público e privada, englobando a educação infantil, ensino fundamental, médio e superior (BRASIL, 1999). Desta forma o Ministério da Educação e desportos (MEC) elaborou os Parâmetros Curriculares Nacionais (PCN) no qual o meio ambiente (Educação Ambiental) faz parte, sendo apresentado como tema transversal para todo o currículo, tratado de forma articulada entre as diversas áreas do conhecimento, de forma a impregnar toda a prática educativa e, ao mesmo tempo, criando uma visão global e abrangente da questão ambiental (GUIMARÃES, 2016, p.12).

Pelo exposto, fica evidenciado o papel relevante da escola na conscientização ambiental das pessoas, agente que constrói senso de responsabilidade, de valores humanizados, os quais, o indivíduo possa repensar suas atitudes e ser capaz de assumir novos posicionamentos na busca de soluções para os problemas socioambientais. Marques et.al, (2014, p.11), corroboram com esta ideia em seu trabalho, dizendo que a Educação Ambiental é uma solução eficaz na formação do indivíduo, onde o mesmo é capaz de entender a problemática atual do meio ambiente e de realizar atos que contribuam para um planeta ecologicamente correto, ou seja, indivíduos que busquem soluções para mitigar os danos causados ao ambiente, para que de forma consciente utilizem os recursos naturais de forma sustentável, contribuindo positivamente para a qualidade de vida das pessoas.

Da mesma forma, Saraiva et. al., (2008, p.84), complementaram dizendo que a Educação Ambiental visa contribuir para cidadãos conscientes de suas responsabilidades com o meio ambiente, sendo necessário que a escola não trabalhe só teoricamente esses assuntos, mas que também esse tema transversal seja uma ferramenta utilizada para que o aluno possa aprender de forma dinâmica, maneiras para transformar a realidade em que vive.

A proposta da Educação Ambiental é contribuir para o desenvolvimento do espírito crítico e solidário entre as pessoas e o meio, fazendo correlações no aspecto político, social, econômico, cultural, ecológico. Educar ambientalmente requer mudanças no modo de pensar e agir, seja de forma individual ou coletiva (PETRIS; SEHNEN, 2011, p.38). A Educação Ambiental deve ser encarada como um exercício da cidadania, em que todos os componentes da sociedade devem ser participantes integrais desse processo (MARQUES et al., 2014, p.12).

revista brasileira educação ambiental 


\section{Escolas do eixo de recursos naturais e a formação profissional em relação às questões socioambientais}

Em escolas as quais são oferecidos cursos cuja modalidade é o ensino técnico profissionalizante integrado ao ensino médio, sendo este curso voltado ao eixo de recursos naturais, é grande a responsabilidade de promover Educação Ambiental, pois esta pode contribuir para a formação de profissionais mais conscientes em relação as questões socioambientais. $O$ Instituto Federal de Educação, Ciência e Tecnologia Fluminense (IFF), oferece educação profissional e tecnológica, com cursos técnicos integrados ao ensino médio, cujo objetivo é formar cidadãos e profissionais que atendam à sociedade e ao mercado de trabalho. De acordo com Silva et. al., (2009, p. 71),

[...] o foco dos institutos federais é a promoção da justiça social, da equidade, do desenvolvimento sustentável com vistas a inclusão social, bem como a busca de soluções técnicas e geração de novas tecnologias. Estas instituições devem responder, de forma ágil e eficaz, às demandas crescentes por formação profissional, por difusão de conhecimentos científicos e de suporte aos arranjos produtivos locais.

Os autores ponderam que a proposta dos Institutos Federais é desenvolver a educação como instrumento de transformação e de enriquecimento do conhecimento, capaz de modificar a vida social e atribuir maior sentido e alcance ao conjunto da experiência humana. O IFF oferece muitos cursos, dentre eles, cursos técnicos voltados para o eixo de recursos naturais, onde o mesmo compreende

[...] tecnologias relacionadas à produção animal, vegetal, mineral, aquícola e pesqueira. Abrangendo ações de prospecção, avaliação técnica e econômica, planejamento, extração, cultivo e produção referente aos recursos naturais. Inclui, ainda, tecnologia de máquinas e implementos, estruturada e aplicada de forma sistemática para atender às necessidades de organização e produção dos diversos segmentos envolvidos, visando à qualidade e sustentabilidade econômica, ambiental e social. Integra a organização curricular dos cursos, a ética, o desenvolvimento sustentável, o cooperativismo, a consciência ambiental, o empreendedorismo, as normas técnicas e de segurança, além da capacidade de compor equipes, atuando com iniciativa, criatividade e sociabilidade (MEC, 2016, p.225). 
que oferece o curso técnico integrado e concomitante em agropecuária e o técnico integrado em agroecologia, ambos voltados para o eixo de recursos naturais, buscando-se dessa forma atuar em favor do desenvolvimento da economia local e regional. De acordo com o Catálogo Nacional de Cursos Técnicos, a definição do profissional técnico em agropecuária e seu respectivo campo de atuação, é aquele que

maneja, de forma sustentável, a fertilidade do solo e os recursos naturais. Planeja e executa projetos ligados a sistemas de irrigação e uso da água. Seleciona, produz e aplica insumos (sementes, fertilizantes, defensivos, pastagens, concentrados, sal mineral, medicamentos e vacinas). Desenvolve estratégias para reserva de alimentação animal e água. Realiza atividades de produção de sementes e mudas, transplantio e plantio. Realiza colheita e pós-colheita. Realiza trabalhos na área agroindustrial. Opera máquinas e equipamentos. Maneja animais por categoria e finalidade (criação, reprodução, alimentação e sanidade). Comercializa animais. Desenvolve atividade de gestão rural. observa a legislação para produção e comercialização de produtos agropecuários, a legislação ambiental e os procedimentos de segurança no trabalho. Projeta instalações rurais. Realiza manejo integrado de pragas, doenças e plantas espontâneas. Realiza medição, demarcação e levantamentos topográficos rurais. Planeja e efetua atividades de tratos culturais (MEC, 2016, p.229).

O Projeto Pedagógico do Curso técnico em agropecuária (PPC) do IFF Cambuci, diz que qualificar profissionais com valorização do desenvolvimento técnico e tecnológico que tenham uma visão de desenvolvimento sustentável é relevante para se aproveitar os diversos recursos naturais para gerar renda e torná-los disponíveis às futuras gerações. Tornando-se de extrema importância a formação de profissionais capacitados na produção vegetal e animal, que saibam utilizar as variadas tecnologias disponíveis e que tenham uma visão sustentável no desenvolvimento agropecuário (IFF, 2016a, p.14). O perfil do profissional técnico em agroecologia e seu campo de atuação é definido como aquele que:

Implanta sistemas de produção agropecuária e agroextrativista e técnicas de sistemas orgânicos de produção. Realiza procedimentos de conservação do solo e da água. Organiza ações integradas de agricultura familiar. Desenvolve ações de conservação e armazenamento de matéria-prima, de processamento e industrialização de produtos agroecológicos. Opera máquinas e equipamentos agrícolas inerentes ao sistema de produção agroecológico. Além de atuar na certificação agroecológica (MEC, 2016, p. 227). 
Segundo o PPC desse Curso no IFF Cambuci, o enfoque agroecológico a ser adotado constitui-se em uma alternativa ao modelo convencional de produção, constituindo-se em um desafio para promover um modelo técnicocientífico que viabilize uma agricultura socialmente não excludente, agregando valores à cadeia produtiva visando assegurar a sustentabilidade social, ambiental e econômica dos agroecossistemas (IFF, 2016b, p.14).

De acordo com os PPCs supracitados, a princípio, escolas que ofertam cursos técnicos agrários, no eixo de recursos naturais, teriam o compromisso de contribuir para a promoção do conhecimento acadêmico, mas também, na formação de profissionais conscientes ambientalmente, valorizando os recursos naturais existentes, tendo o auxílio da Educação Ambiental como base para o desenvolvimento sustentável.

\section{Metodologia}

Este trabalho foi realizado no Instituto Federal de Educação, Ciência e Tecnologia Fluminense (IFF) campus avançado Cambuci, localizado na Fazenda Santo Antão, Km 5, estrada Cambuci - Três Irmãos, (Latitude $=21^{\circ}$ $35^{\prime} 14.29 " \mathrm{~S}$; Longitude $=41^{\circ} 57^{\prime} 30.02^{\prime \prime} \mathrm{O}$ ), na zona rural do município de Cambuci, RJ. A escola dispõe de uma infraestrutura adequada para a difusão de conhecimento prático e técnico, possibilitando o desenvolvimento e profissionalização na área agrícola tendo em vista que a região noroeste é predominantemente agropecuária, contribuindo para o fortalecimento desse setor no interior do estado (IFF, 2016a, p. 7)

A metodologia utilizada nesta pesquisa foi quali-quantitativa, com a coleta de dados por meio da aplicação de questionários estruturados, composto por perguntas fechadas e abertas, para estudantes de nível médio técnico integrado em agropecuária e agroecologia, sendo aplicado em 26 de abril de 2017, pela manhã, para um total de 64 alunos, sendo formado por 37 alunos do curso técnico de agropecuária (24 alunos do $2^{\circ}$ ano e 13 alunos do $3^{\circ}$ ano) e 27 alunos do curso técnico de agroecologia (19 alunos do $2^{\circ}$ ano e 8 alunos do $3^{\circ}$ ano), onde todos foram avaliados, exceto aqueles alunos ausentes.

\section{Resultados e discussão}

Analisando os resultados obtidos, constatou-se que dos 64 alunos avaliados, a maioria era do gênero feminino (58\%) e $42 \%$ do gênero masculino. A faixa etária predominante foi entre 15 a 17 anos.

Em relação ao local de residência dos alunos, observou-se que a maioria reside na zona urbana do município de Cambuci e região ao entorno, tendo uma minoria residentes da zona rural. No curso de agropecuária são $81 \%$ dos alunos residindo na área urbana e $67 \%$ da agroecologia, sendo $19 \%$ e $33 \%$ desses discentes residentes da zona rural respectivamente. Mesmo Revbea, São Paulo, V. 13, № 2: 246-263, 2018. 
residindo na zona urbana, todos os alunos têm contato com o campo, devido terem propriedades de familiares e amigos nos distritos do município e de municípios periféricos.

Em relação ao motivo da escolha do curso técnico, observou-se um grande contraste de respostas de um curso para o outro. Nos Gráficos 1 e 2, pode-se observar tal contraste na motivação da escolha do curso.

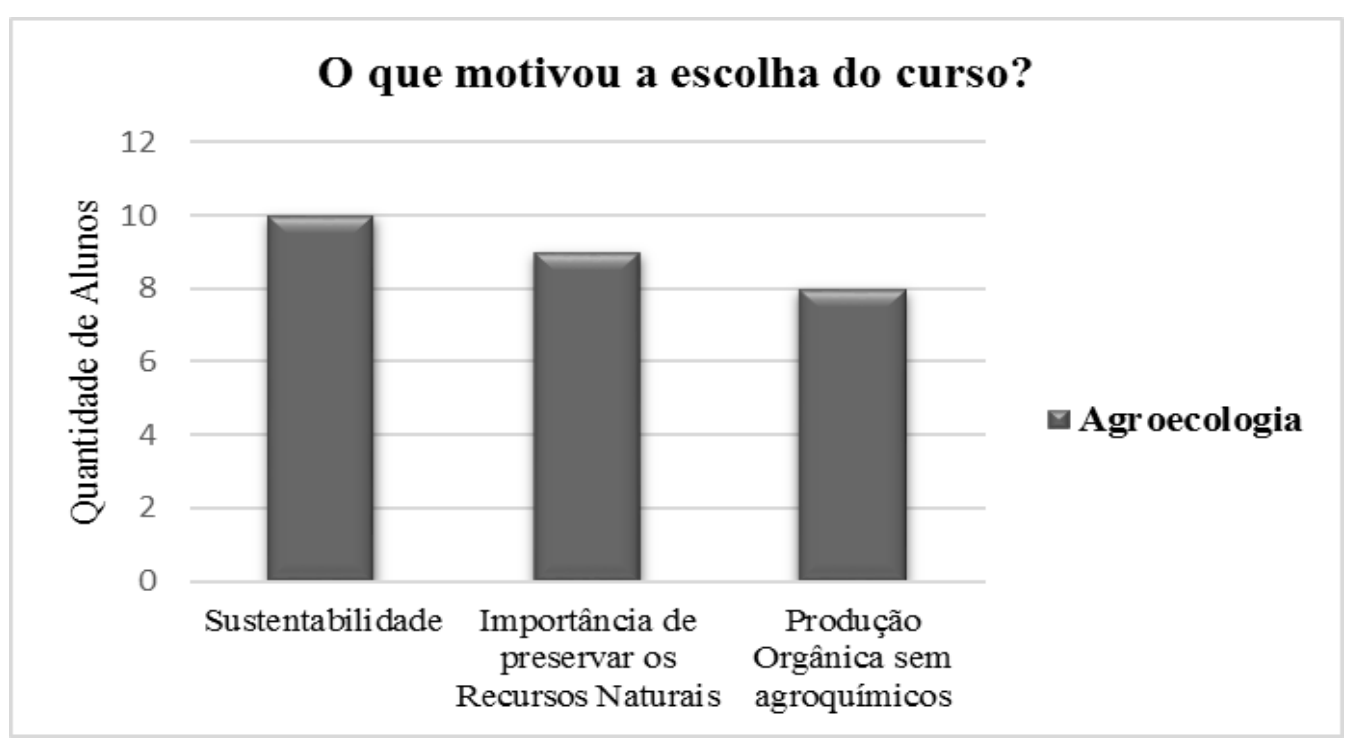

Gráfico 1: Respostas dos alunos do Curso de Agroecologia em relação ao motivo da escolha do curso.

Dos 27 alunos deste curso de agroecologia, 10 alunos (37\%) responderam que escolheram esse curso devido as atividades sustentáveis que o curso oferece em relação à produção agrícola, 9 (33\%) dos alunos responderam sobre a importância da preservação dos recursos naturais e 8 $(30 \%)$ dos discentes responderam que o curso ensina o aluno a produzir alimentos orgânicos isentos de agroquímicos.

Vale destacar algumas respostas apresentadas por estes alunos:

- "Porque na agroecologia aprendemos a produzir de modo sustentável."

- "Por eu ser morador da zona rural eu tenho um conhecimento sobre os moradores da roça, que é um povo simples, seria muito bom que eu soubesse como fazer as tarefas e atividades rurais de forma sustentável e econômica para que um dia eu possa repassar meus conhecimentos."

- "Pela área buscar uma sustentabilidade e buscar sempre medidas alternativas para o bem estar do meio ambiente." 
Já, no curso de agropecuária (Gráfico 2), as respostas dos alunos basearam-se na indicação de amigos e familiares, sendo $5(13 \%)$ respostas baseadas nesse parâmetro, outros 5 alunos (13\%) responderam devido à escola ser uma instituição federal e que oferece um ensino de qualidade, 13 alunos (35\%), responderam baseado na ideia de que o curso oferece uma maior disponibilidade de emprego em relação ao de agroecologia, e os outros $14(38 \%)$ dos alunos amostrados, responderam que escolheram o curso devido a concepção que eles tem de uma produção de alimentos em grande escala em relação ao curso de agroecologia que é mais familiar.

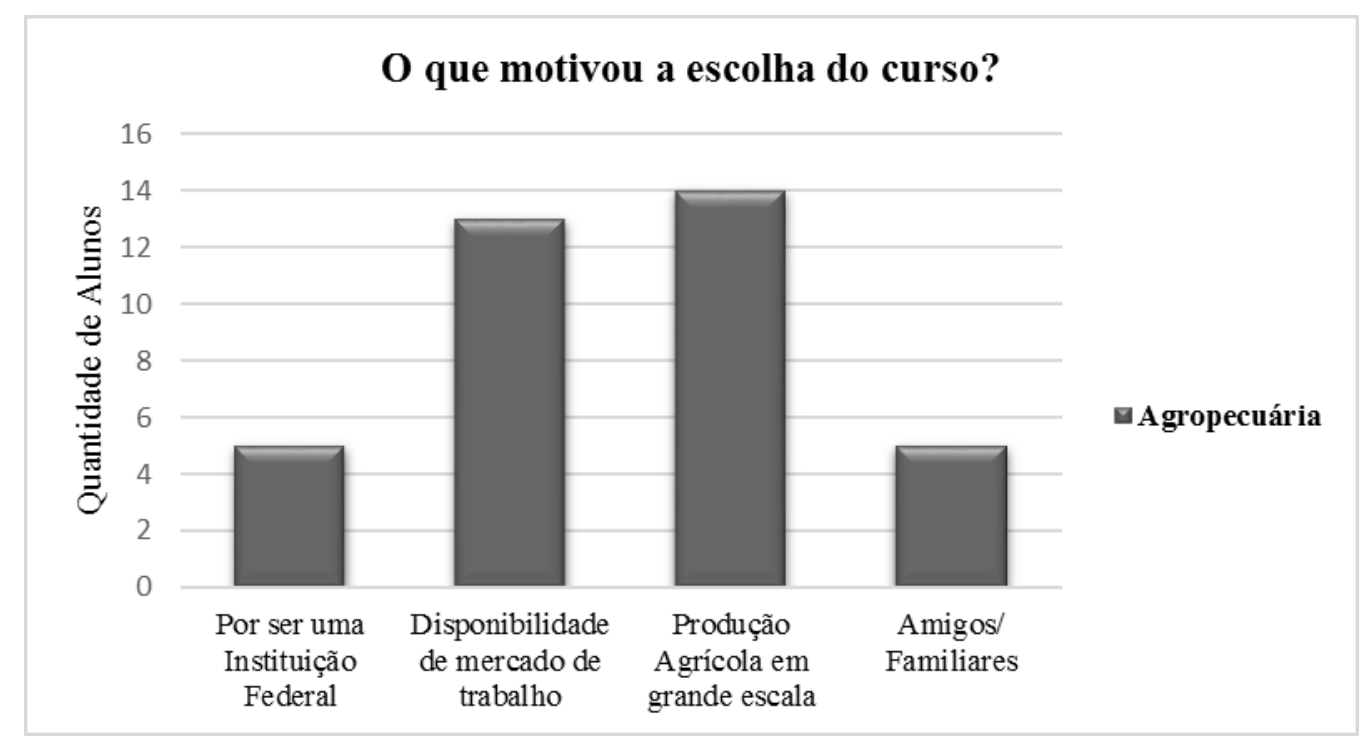

Gráfico 2 : Respostas dos alunos do Curso de Agropecuária em relação ao motivo da escolha do curso.

Observa-se assim, o que mais chamou atenção para a escolha desse curso é a disponibilidade de mercado de trabalho e a produção da agropecuária dita como convencional, tradicional, com grande produtividade. Isso pode ser corroborado pela amostra de respostas a seguir.

- "Escolhi pois pretendo seguir na área e o curso irá me dar base, e há maior oportunidade de trabalho nas propriedades da região."

- "Por eu gostar da área de agropecuária, por conta de ser federal, gratuita e por ter ensino de qualidade."

- "O fato da produção em grande escala ser mais fácil na agropecuária."

O mesmo foi constatado por Brandão (2015, p.8), que ao analisar os fatores e áreas que influenciam na escolha do curso técnico em agropecuária do IFF campus Cambuci em 2015, ela comprovou que, dentre os fatores, "o fato de ser gratuito", "a possibilidade de atuar em diversas áreas", "a 
possibilidade de obter o CREA", "a possibilidade de realização profissional", "empregabilidade da profissão", "vocação", "o prestígio da instituição", e a "disponibilidade de vagas em concurso público" foram considerados como essenciais para escolha do curso por percentuais que variam de 76,5 a $89,9 \%$ dos 57 alunos avaliados.

O Gráfico 3 ilustra o cenário referente às expectativas profissionais dos alunos após concluírem o curso técnico. Pode-se identificar que dos 64 alunos avaliados, $45 \%$ deles querem cursar o nível superior na área do técnico, entre os cursos citados destaca-se agronomia, medicina veterinária e zootecnia. Destes alunos, $33 \%$ são do curso técnico em agroecologia e $54 \%$ do curso de agropecuária, nota-se, como os cursos técnicos podem influenciar na escolha do curso superior, e também devido ao contato que os alunos têm com o meio rural cotidianamente e da necessidade de crescer academicamente na área agrária para poder atuar nesse campo de trabalho. Observa-se também, uma grande indecisão dos alunos ao escolher o que cursar, surgindo nessa fase da vida, muitas dúvidas em relação ao futuro profissional.

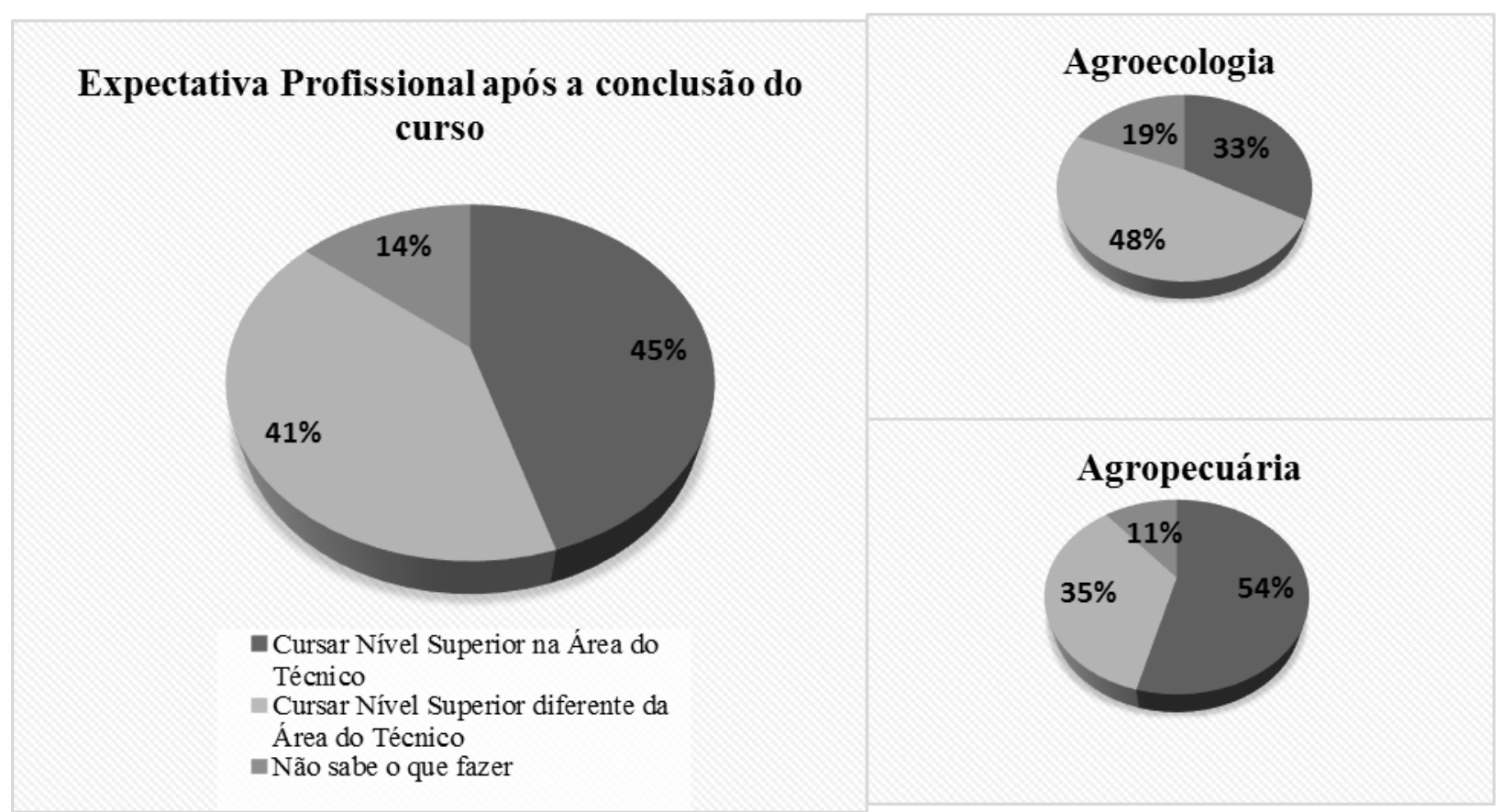

Gráfico 3: Expectativas Profissionais dos Alunos após a conclusão dos cursos.

Solicitou-se a atribuição de notas de $0-10$, em relação ao nível de interesse por parte dos alunos por assuntos relacionados ao meio ambiente, sendo 0 o menor nível de satisfação e 10 o maior. Obteve-se como média a nota 8, para os dois cursos baseada nas respostas dos 64 alunos avaliados. No Gráfico 4, pode-se observar as notas atribuídas separadamente pelo quantitativo de alunos participantes. Destaca-se (40\%) 11 alunos de agroecologia com nota 8 e $22 \%$ deles com as notas 9 e 10 . E do curso de agropecuária foram 13 alunos (35\%) votaram com nota 10 e $24 \%$ com nota 8 . 
Observa-se assim, um grande interesse por parte dos discentes pelas questões ambientais existentes.

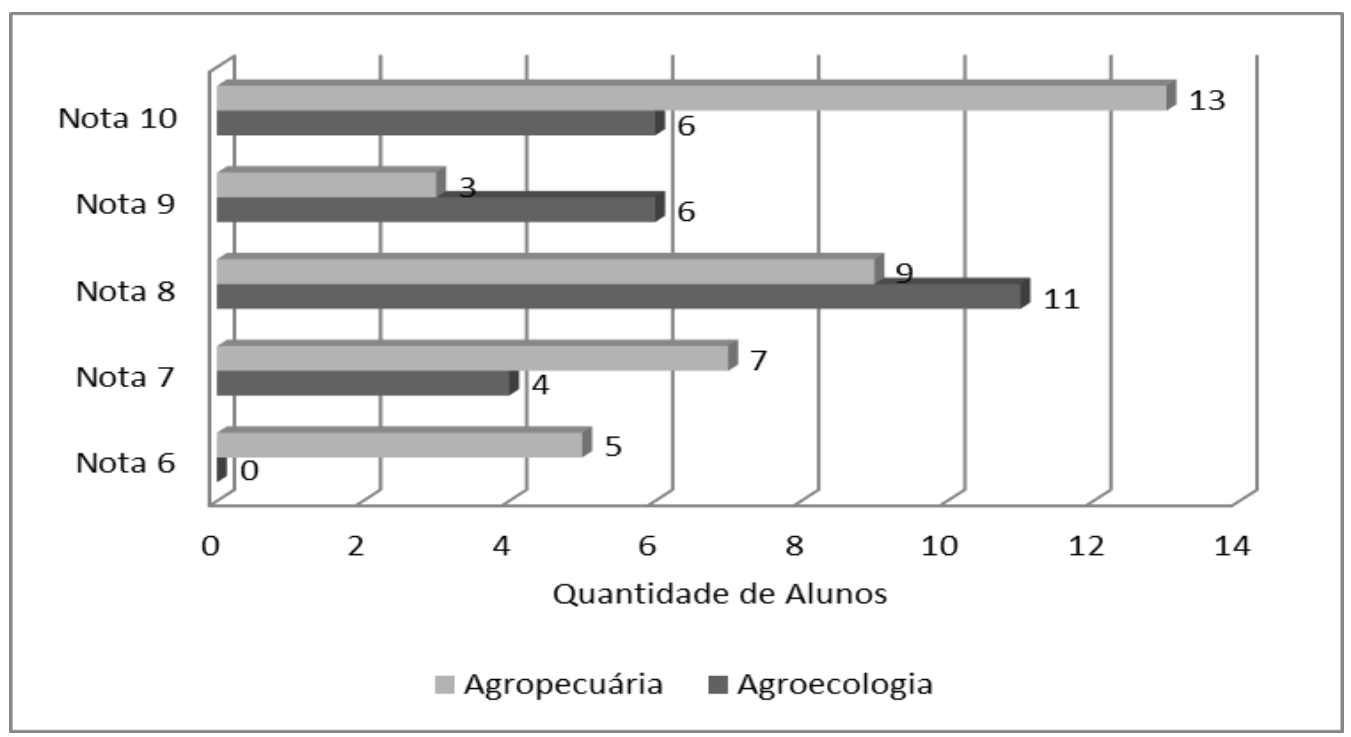

Gráfico 4: Nível de interesse por assuntos relacionados com o meio ambiente dos alunos dos cursos técnicos de agropecuária e agroecologia do IFF Cambuci.

Questionou-se aos discentes avaliados, se o curso técnico integrado tem contribuído no desenvolvimento de práticas sustentáveis e de que forma. Obtendo-se $100 \%$ de aprovação dos alunos do curso de agroecologia, podendo ser visualizado abaixo no Gráfico 5.

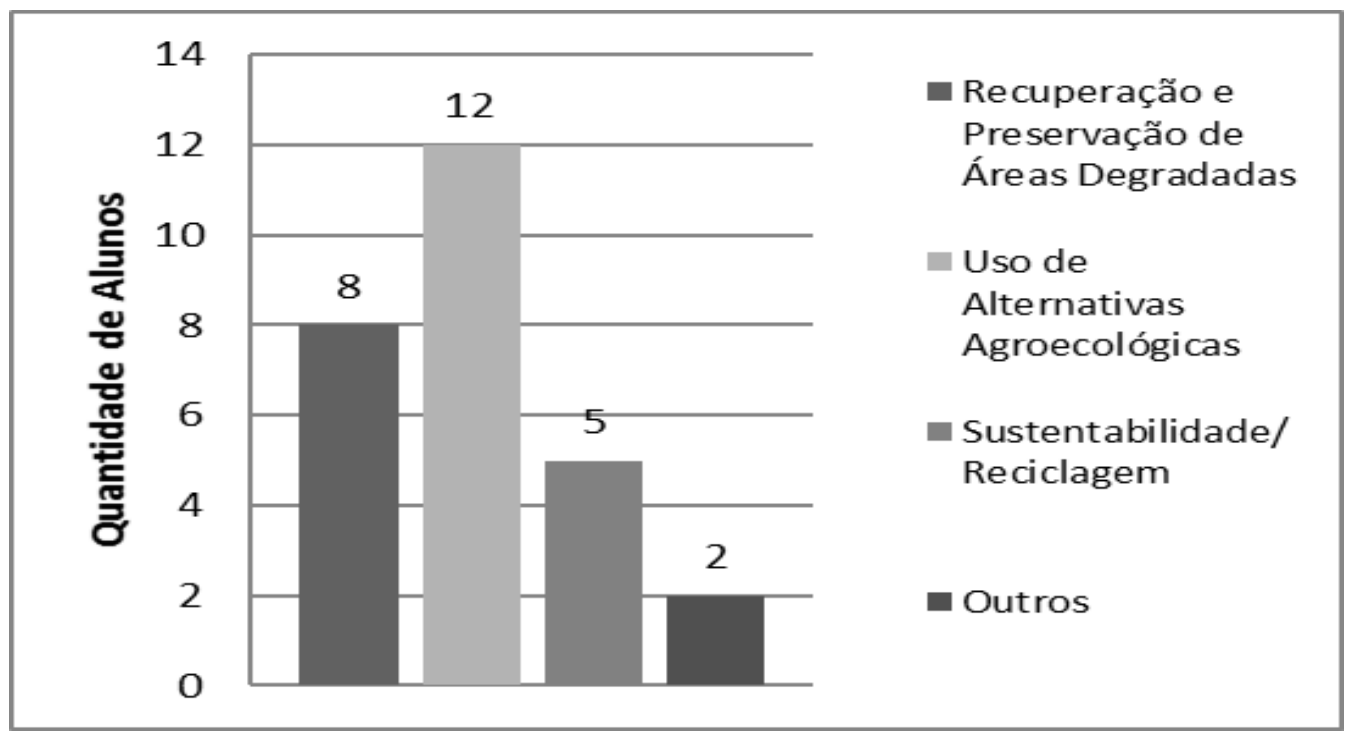

Gráfico 5: Aprovação dos Alunos em relação à contribuição do curso de agroecologia no desenvolvimento de práticas sustentáveis.

Revbea, São Paulo, V. 13, № 2: 246-263, 2018. 
Como visualizado, a maioria dos alunos (44\%), citaram o uso de alternativas agroecológicas, $30 \%$ dos alunos responderam pela recuperação e preservação de áreas degradadas, $19 \%$ deles pelas questões de sustentabilidade. Sendo mencionado nas respostas à recuperação de áreas de preservação permanente (APP), falaram sobre a importância de economizar água e sobre o lixo gerado e a coleta do mesmo que é realizada na escola. Comentaram também sobre a produção de animais visando o bem-estar dos mesmos e do ambiente, falaram do uso de caldas e adubos alternativos na produção de alimentos. E os outros $7 \%$ entrevistados, falaram que o curso contribui para a conscientização ambiental deles, porém não especificaram como.

Estes dados mostram o quanto a escola tem contribuído por meio da Educação Ambiental para a conscientização dos alunos, cumprindo com que propõe no PPC desse curso, onde o mesmo visa atender à demanda regional por meio de profissionais habilitados para a realização, orientação e gerenciamento dos processos de produção e transformação de produtos agropecuários, segundo os princípios da agroecologia. Desempenhando suas atividades, demonstrando um elevado grau de responsabilidade social, no uso de meios naturais ou ecologicamente seguros, garantindo a produtividade econômica das culturas, promovendo assim a segurança alimentar e a sustentabilidade da agricultura (IFF, 2016b, p.13).

No Gráfico 6, é mostrado as respostas dos alunos do curso técnico em agropecuária em relação à contribuição do mesmo para práticas sustentáveis desses discentes.

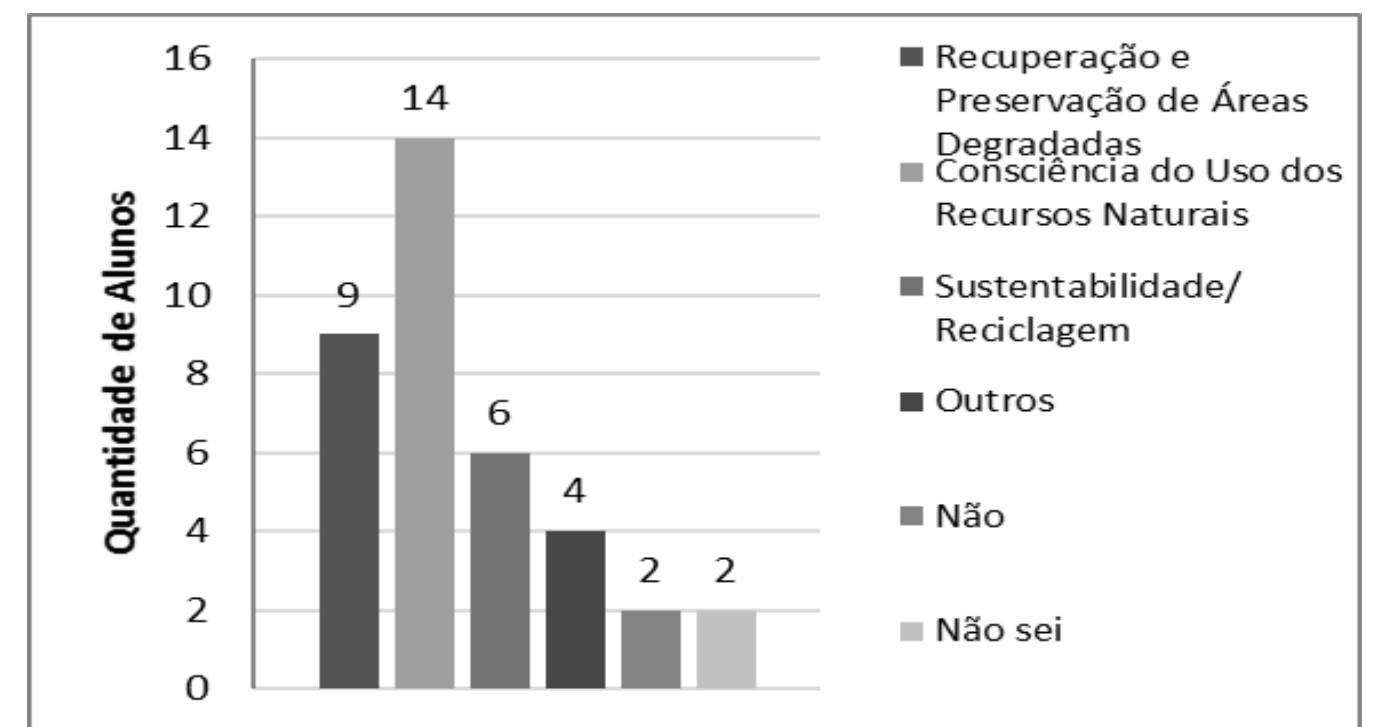

Gráfico 6: Aprovação dos Alunos em relação à contribuição do curso de agropecuária no desenvolvimento de práticas sustentáveis.

Pode-se observar que dos 37 alunos do curso de agropecuária, 33 deles $(90 \%)$, disseram que o curso contribui com práticas sustentáveis, sendo que 
$5 \%$ dos alunos não souberam dizer e outros $5 \%$ negaram a contribuição do curso, percebe-se que nenhum desses dois últimos parâmetros têm justificativa da sua negação em relação a esse quesito. Em relação a maneira como ocorre tal contribuição, vê-se que 14 desses alunos (39\%), responderam devido a utilizar os recursos naturais de forma consciente e sustentável, desenvolvendo práticas agrícolas com um olhar mais sensível em relação as questões ambientais, 9 alunos (24\%) disseram da importância da recuperação e preservação de áreas degradadas, outros 16\% falaram sobre práticas de sustentabilidade e reciclagem que vivenciaram na escola e que contribuíram de alguma forma para o desenvolvimento da consciência ambiental deles, e outros $11 \%$ não especificaram como, ou quais atividades realizadas no curso contribuíram para a conscientização, justificaram dizendo que foi por meio das aulas teóricas e práticas e em estágios realizados. Outros $10 \%$ foram os alunos que não souberam dizer e os que negaram a contribuição da escola com práticas sustentáveis.

Pode-se notar que da mesma forma que no curso de agroecologia, a escola também tem cumprido seu papel de formar alunos mais preocupados com as questões socioambientais no curso de agropecuária. Diferentemente, foi observado por Moreira (2009, p.8), que ao analisar a Educação Ambiental e o desenvolvimento da consciência ambiental no ensino e na formação dos alunos do $2^{\circ}$ ano do curso técnico agrícola no colégio agrícola campus III da Universidade Federal da Paraíba (UFPB), demonstrou que a Educação Ambiental vem sido desenvolvida de forma insatisfatória, inviabilizando o desenvolvimento da consciência ambiental dos alunos, propondo a capacitação de docentes com abordagem interdisciplinar e ambiental e que a escola desenvolva trabalhos de Educação Ambiental sobre as questões ambientais existentes, promovendo ações de integração, divulgação e discussão das atividades desenvolvidas.

No Gráfico 7 a seguir, pergunta-se a importância da formação ambiental nos cursos agrários e, podemos observar que $78 \%$ dos alunos de agroecologia e $68 \%$ dos alunos de agropecuária afirmam que é muito importante e os outros $22 \%$ e $32 \%$ afirmaram ser importante, mostrando-se como é importante que esses cursos se baseiem nas questões socioambientais e na formação de profissionais bem informados quanto a essas questões. 


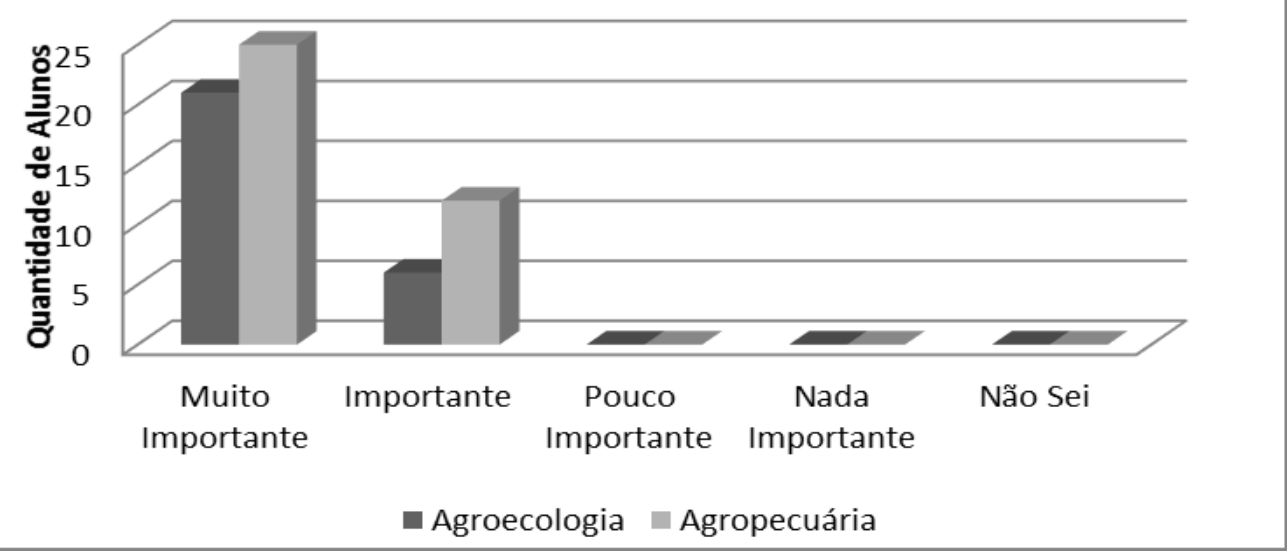

Gráfico 7: Avaliação quanto à importância da formação ambiental dos cursos técnicos agrários para os alunos do curso de agroecologia e agropecuária do IFF campus Cambuci.

Pediu-se aos 64 alunos entrevistados que avaliassem com que frequência são tratados assuntos relacionados ao meio ambiente na escola, sendo mostrado no Gráfico 8. Pode-se identificar que a maioria dos alunos afirmaram que a escola fala sobre questões ambientais, sendo que $41 \%$ disseram que a escola sempre fala sobre essas questões e $48 \%$ disseram com alguma frequência, demonstrando que a escola segue o que a legislação e o PCN preconizam, promovendo a Educação Ambiental de forma transversal em consonância ao conteúdo propedêutico e também do técnico. Costa et. al., (2006, p. 68), ao avaliarem os alunos de diversos cursos técnicos integrados do CEFET- RN, obtiveram resultados diferentes em relação a esse mesmo parâmetro, demonstrando que $75 \%$ dos alunos disseram que não tem a inserção desse tema nas disciplinas cursadas na escola.

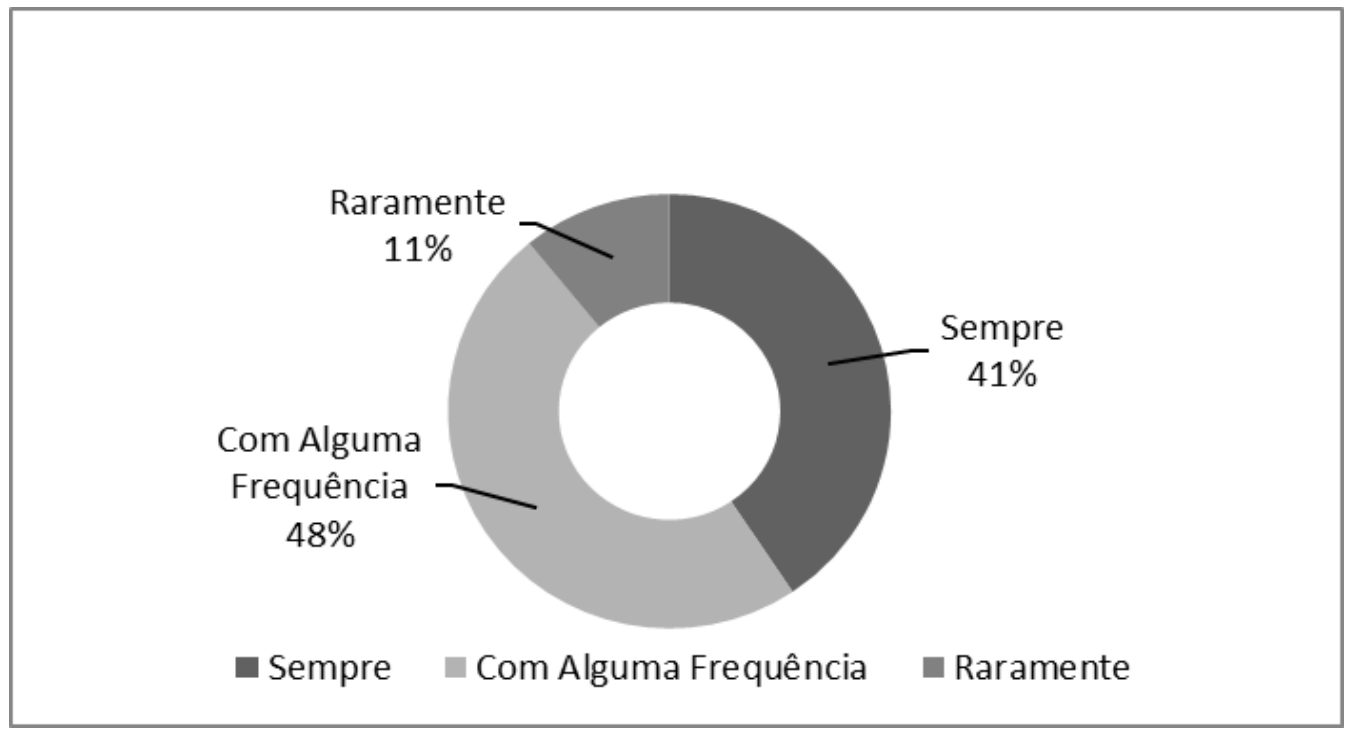

Gráfico 8: Avaliação dos alunos de agroecologia e agropecuária quanto à frequência que são tratados assuntos relacionados com o Meio Ambiente no IFF Cambuci.

Revbea, São Paulo, V. 13, № 2: 246-263, 2018. 
Nos Gráficos 9 e 10 abaixo, trata-se de atividades que os alunos do IFF Cambuci dos cursos de agroecologia e agropecuária fazem na escola que contribuem de alguma forma no desenvolvimento da consciência ambiental. $E$ pode-se observar que os cursos, por meio do que prioriza em seu Projeto Pedagógico de Curso e no Catálogo Nacional de Cursos Técnicos, tem cumprido seu papel contribuindo significativamente para a sensibilização e consequentemente para a conscientização em relação as questões ambientais existentes. Abaixo visualiza-se as respostas dos alunos entrevistados, onde identifica-se algumas atividades que os alunos desempenham na escola nas atividades de estágios, aulas teóricas e práticas, projetos de pesquisa e extensão e semanas acadêmicas.

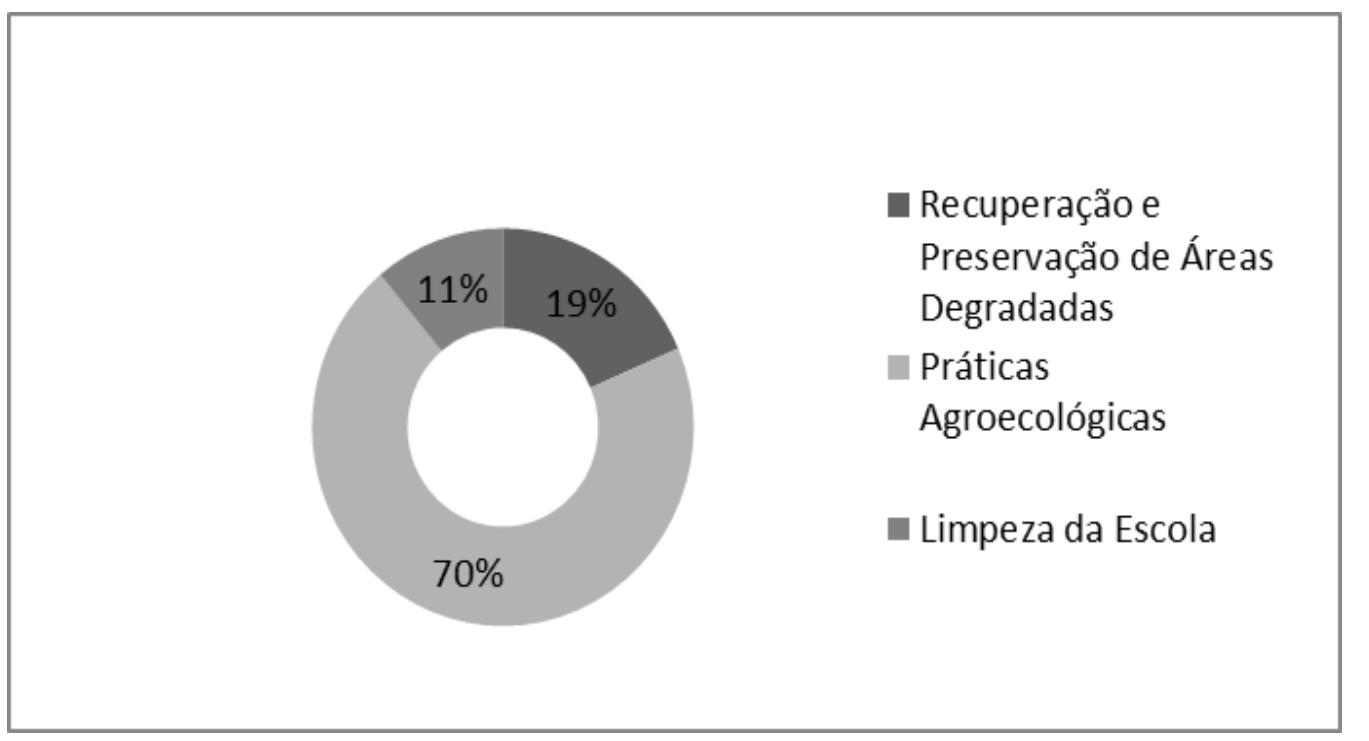

Gráfico 9: Atividades Desenvolvidas no Curso de Agroecologia que contribuem para o desenvolvimento da consciência ambiental. 


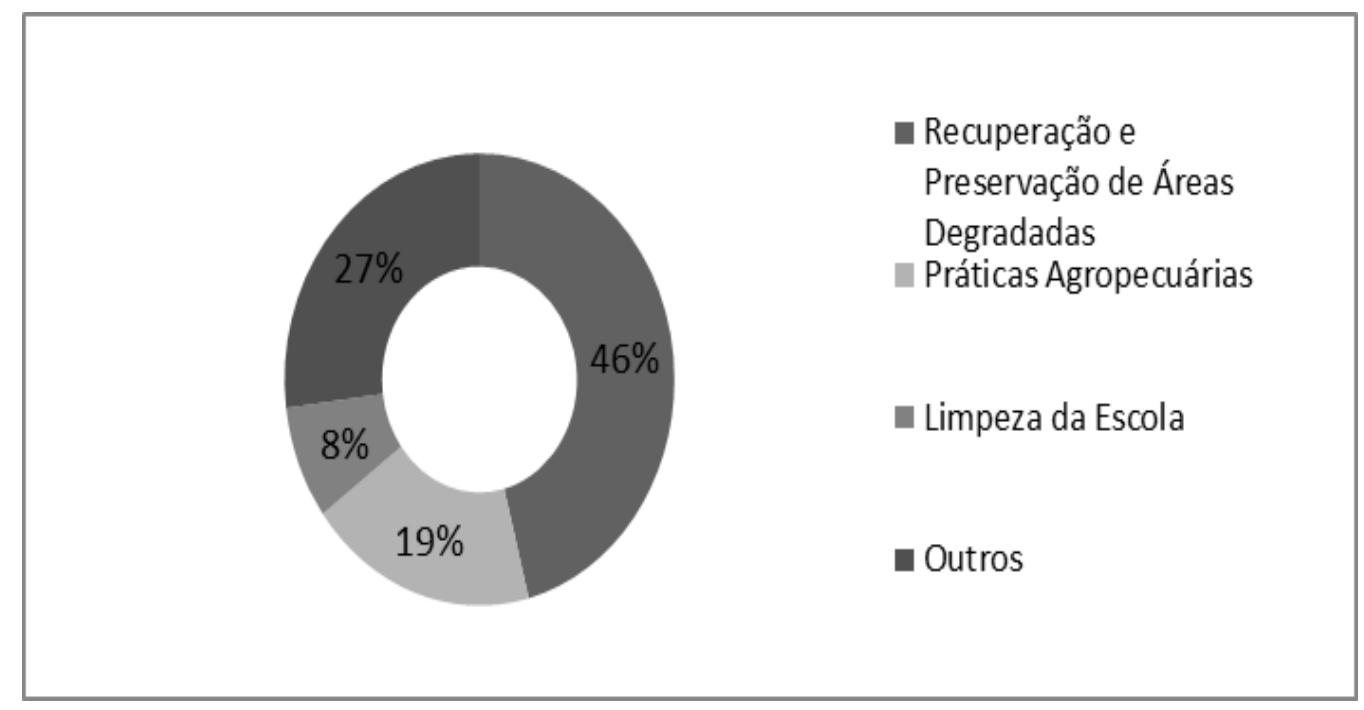

Gráfico 10: Atividades desenvolvidas no Curso de Agropecuária que contribuem para o desenvolvimento da consciência ambiental.

Ao analisar as respostas dos 37 alunos do curso de agropecuária, vemos que $46 \%$ deles disseram que atividades relacionadas à recuperação de áreas de preservação permanentes que foram degradadas, são importantes devido ao valor ambiental e que o dever como sociedade de recuperar essas áreas tão essenciais pra vida. Outros $27 \%$ dos alunos, citaram apenas que foi por meio de palestras na semana acadêmica, minicursos e aulas, não especificando quais atividades do curso que contribuíram no desenvolvimento de práticas sustentáveis. Cerca de $19 \%$ dos alunos, justificaram que foram por meio de atividades práticas agropecuárias de produção, sendo citado nas respostas, a produção de mudas florestais para plantio de árvores para recuperação de matas ciliares e topos de morros degradados, produção de húmus como fertilizante alternativo de forma a complementar o método convencional que é o uso de fertilizantes minerais, controle de daninhas por métodos alternativos além do químico como a capina manual, análise da qualidade da água dos tanques de piscicultura, com objetivo de produzir de forma a mitigar a contaminação de corpos d'água, minimizando ao máximo os resíduos gerados por essa atividade, plantio de culturas em curva de nível de forma conservacionista, dentre outros. $8 \%$ mencionaram que a limpeza da escola também foi outra atividade realizada durante o curso que contribuiu de alguma forma para a conscientização, sendo citado a coleta de lixo no pátio e aproveitamento desses materiais para reúso no próprio campus.

Dentre os resultados obtidos, a partir das respostas dos alunos, destacase que os dois cursos apresentam aos estudantes várias questões de produção agrícola os quais preconizam-se o uso sustentável dos recursos naturais. Por isso ressalta-se a importância da escola na formação do profissional com uma visão sustentável e ambientalista. $A$ análise do ambiente pelos alunos propicia uma ampla discussão dos aspectos biológicos, geográficos, históricos, políticos, econômicos, sociais e culturais, visando a leitura da realidade e 
possível intervenção. Assim, envolver os alunos em atividades interessantes onde há participação, pesquisa, envolvimento e integração é a garantia de desenvolver o conhecimento sobre as questões ambientais (SILVA, 2003, p. 53).

Por fim, foi questionado aos alunos de que forma ou quais atividades eles sugeririam que fossem realizadas na escola para melhoria da consciência ambiental de toda a comunidade escolar, abrangendo inclusive os servidores e terceirizados. As respostas foram bem aproximadas em relação aos dois cursos, ressaltando-se a importância de realizar uma maior quantidade de palestras, minicursos e projetos com finalidade ambiental, distribuição de lixeiras divididas para reciclagem pela escola, campanhas de sensibilização e conscientização ambiental dentro e fora do campus, por meio da distribuição de panfletos educativos, espalhar placas ou cartazes pela escola com informativos sobre questões ambientais com incentivo à sustentabilidade, podendo-se perceber que a Educação Ambiental deve ser também para toda a comunidade escolar, sendo uma responsabilidade conjunta de todos da escola.

\section{Conclusão}

Portanto, através dos resultados obtidos nesse trabalho, conclui-se que o Instituto Federal de Educação, Ciência e Tecnologia Fluminense campus avançado Cambuci, tem promovido a Educação Ambiental, contribuindo no desenvolvimento da consciência ambiental dos alunos dos cursos do eixo de recursos naturais de agropecuária e agroecologia ofertados.

\section{Referências}

ALMEIDA, A.F. Preservação Ambiental, o Homem e o Planeta Ameaçado. Curvelo, MG, 2011. 26 p.

BRANDÃO, C. C. Validação de fatores e áreas que influenciam na escolha pelo curso técnico em agropecuária no Instituto Federal Fluminense Campus Cambuci. 2015. 109 f. Dissertação (Mestrado em Engenharia de Produção) Universidade Candido Mendes, Campos dos Goytacazes, RJ, 2015.

BRASIL. Constituição da República Federativa do Brasil (1988). Brasília, DF. p. 93. Disponível em: http://www.planalto.gov.br/ccivil 03/ constituicao/constituicaocompilado.htm. Acesso em: 05 de Abril, 2017.

BRASIL. Lei no 9.795, de 27 de abril de 1999. Dispõe sobre a Educação Ambiental, institui a Política Nacional de Educação Ambiental e dá suas providências. Disponível em: http://www.mma.gov.br/port/conama/legiabre. cfm?codlegi=321. Acesso em: 05 de Abril, 2017.

COSTA, A.P.B.; PAIVA, M.S.D.; FILGUEIRA, J.M. A inserção da Educação Ambiental na prática pedagógica: uma análise segundo a visão dos alunos dos cursos técnicos integrados do CEFET-RN. Holos, n.22, p. 62-73, 2006. 
CUBA, M.A. Educação Ambiental nas escolas. ECCOM, v. 1, n. 2, p. 23-31, Jul./Dez. 2010.

GREGORI, M.S.; ARAÚJO, L.E.B. Epistemologia Ambiental: A crise ambiental como uma crise da razão. Anais do I Congresso Internacional de Direito Ambiental e Ecologia Política -UFSM, e III Seminário Ecologia Política e Direito na América Latina, 2013. Revista Eletrônica do Curso de Direito, Santa Maria: UFSM, 2013, ISSN 1981-3694, v.8, p. 700 - 711.

GUIMARÃES, M. Por uma Educação Ambiental crítica na sociedade atual. Revista Margens Interdisciplinar, v.7, n.9, p.11-22, 2016.

INSTITUTO FEDERAL FLUMINENSE. Projeto pedagógico de curso técnico integrado ao ensino médio, técnico em agropecuária. Cambuci, RJ. 2016a. $150 \mathrm{p}$.

INSTITUTO FEDERAL FLUMINENSE. Projeto pedagógico de curso técnico integrado ao ensino médio, técnico em agroecologia. Cambuci, RJ. 2016b. $157 \mathrm{p}$.

MARQUES, M.L.A.P.; SILVA, A.F.; ARAÚJO, J.E.Q.; QUEIROZ, T.H.S.; ALMEIDA, I.D.A.; MARINHO, A.A. A Educação Ambiental na Formação da Consciência Ecológica. Cadernos de Graduação: Ciências exatas e tecnológicas, Maceió, v. 1, n.1, p. 11-18, maio 2014.

MEC. Catálogo Nacional de Cursos Técnicos. Ministério da Educação, $3^{\underline{a}}$ ed. Brasília, DF, 2016. 288 p. Bibliografia: p. 225 - 229.

MEC. Processo Formativo em Educação Ambiental: Escolas Sustentáveis e COM-VIDA. Ministério da Educação, Secretaria de Educação Continuada, Alfabetização e Diversidade. Brasília, DF, 2010. 58 p.

MOREIRA, J.S. A Educação Ambiental na Formação do Técnico Agrícola. 2009. 99f. Dissertação (Mestrado em Educação) - Universidade Federal da Paraíba, João Pessoa, 2009.

PETRIS, M.R.; SEHNEN, I. A Importância da Educação Ambiental. Maiêutica Curso de Ciências Biológicas, v.1, n.1, p. 37-43, Jul./Dez. 2011.

SARAIVA, V.M.; NASCIMENTO, K.R.P.; COSTA, R.K.M. A Prática Pedagógica do Ensino de Educação Ambiental nas Escolas Públicas de João Câmara RN. Holos, v. 2, n.24, p. 81-93, 2008.

SILVA, A.S.M.N. Um Olhar sobre a Educação Ambiental no Ensino Médio: Praticar a Teoria, Refletir a Prática. 2003. 103f. Dissertação (Mestrado em Engenharia de Produção) - Universidade Federal de Santa Catarina, Florianópolis, 2003.

SILVA, C.J.R.; VIDOR, A.M.; PACHECO, E.M.; PEREIRA, L.A.C. Institutos Federais: Lei 11.892, de 29/12/2008 comentários e reflexões. Natal: IFRN, 2009. 70 p. Disponível em: http://www.ifb.edu.br/attachments/4713 Lei\%20n\% C2\%BA\%2011.892\%20-\%20Comentada.pdf. Acesso em: 03 de Maio, 2017. 